\title{
Analysis of the Film "Manslaughter" by Using Semiotic Paradox
}

\author{
Liying Liu* \\ School of Grammar and Law, Nanchang Aviation University, Nanchang 330038, Jiangxi Province, China \\ *Corresponding author: Liying Liu, liuliying0329@163.com
}

\begin{abstract}
Manslaughter" is a crime film released in mainland China on December 13, 2019. Once released, the film has attracted much attention from the audience, surpassing many works released during the same period. The setting of the film and the use of screen language are the magic weapons for the success of the film by gaining favor from the public. This film will be elaborated on based on the field of semiotics.
\end{abstract}

Keywords: Manslaughter; Film semiotics; Film meaning; Semiotic paradox

Publication date: December 2021; Online publication: January 24, 2022

\section{Introduction}

The film "Manslaughter" is a crime film produced by Chen Sicheng, starring Xiao Yang, Tan Zhuo, and Chen Chong. This film was adapted from the Indian film "Drishyam." Li Weijie, played by Xiao Yang, is an avid fan of movies. His eldest daughter, Pingping, was raped by Su Cha, the son of the police chief. The story becomes complicated when Pingping accidentally kills Su Cha. In order to protect his family, Li Weijie used the technique of "lens editing and special effects" from films to create a complete alibi. It is a story of desperate struggle with the police both, physically and mentally ${ }^{[1]}$.

According to Ferdinand Saussure, a Swiss linguist, semiotics is the study of symbols. This is generally accepted as the definition of semiotics. What are symbols then? According to Zhao Yiheng, a doctoral supervisor of semiotics, symbol is perceived as carrying meaning. This concept clearly shows the relationship between symbol and meaning. Meaning needs to be expressed by symbols, which are the carrier of meaning; similarly, there is no symbol that can be separated from meaning, and no meaning can exist independently from symbols. Based on this, Zhao Yiheng proposed the theory of semiotic paradox. This theory has been fully applied in the plot design and screen language of the film "Manslaughter."

\section{Explaining the meaning of absence}

The presence of symbols means that the explanatory meaning of symbols or one of the explanatory meanings is absent. This is the first principle of semiotic paradox. Symbol is regarded as the perception of meaning, which has the potential to reveal meaning. Symbols and their corresponding meanings are not present at the same time; this is apparent in the use of indicators. For example, when driving, the sharp turn is not seen directly by the drive at the time when he or she sees the sharp turn sign; if one can recognize the direction, one does not need a compass ${ }^{[2]}$. These symbols are received by the human brain in order to stimulate consciousness and interpretate the symbols. However, in different contexts, the interpretation of the meaning of these symbols will be different. At the 83rd-minute of the film, La Xuan, the police chief, ordered several people to beat Li Weijie's family to force out the truth. In this scene, La Xuan turned her back to the camera and faced a campaign poster with Su Cha's father, Du Peng, on it, who was a mayoral 
candidate then. This poster appeared many times in the film. Each time it appeared, it represented Du Peng's absence in the scene and deeply expressed his role as a father in the family in addition to his absence in the face his children's education.

Symbols are transmitted to the consciousness of the human brain to stimulate consciousness and explain. There is a time gap before the human brain perceives the explanatory meaning; this is the cognitive difference. The cognitive difference determines the capability to understand a certain meaning. As for the film, moderate cognitive difference is conducive to driving the audience's sense of participation. The following parts of the film provide the audience various possibilities, thus bringing a sense of design and depth rather than putting up facts simply. At the beginning of the film, Pingping visited the tower of repentance. This is the first time that the golden pagoda appeared in the film. When listening to the guide unfolding the story of the tower, Pingping looked pious but Su Cha showed a cynical attitude. This reflects the darkness of Su Cha's personality, which paves the way for the subsequent plot. The second time the tower appeared is at the 97th-minute of the film, where Li Weijie confessed. At this time, the bell of the golden pagoda rang, suggesting that Li Weijie is repenting from his crime and would pay for his actions. A moderate symbolic hint will pave the way for the coherent and smooth development of a plot.

\section{Using symbols to lead meaning}

Meaning can only be derived from symbols, and the purpose of symbols is to derive meaning. The mayoral candidate, Du Peng, and the police chief first appeared in the film to talk about how to solve the accident where $\mathrm{Su}$ Cha stabbed someone. From the dialogue between husband and wife as well as the rival play between father and son, it can be seen that Du Peng tried his best to suppress all the ugly things that his son did in order to succeed in the election. Su Cha's poor temperament is reasoned by his background, which makes the story more three-dimensional. At the 85th-minute of the film, when the police brought An An to a room to press for more information about the case, she stood up, and her shadow fell over An An. The shadow indicated that darkness is coming, and the family might fall into darkness.

The absence of meaning requires symbols. The purpose of the existence of symbols is to remind people that there is meaning waiting to be found. Therefore, a prompt screen with instructive significance needs to be set in the movie. At the 47th-minute, during the construction of the new police station, Li Weijie was paying close attention to the cement floor. The close-up of the floor is instructive here, indicating that it might be related to the case. In front of the construction site of the police station, Sang Kun killed a goat when intimidating Li Weijie. Further up the film, the police dug out a sheep's body from its grave. At this time, the audience would naturally link the missing body with the cement floor at the construction site that was shown earlier in the movie. In fact, there is no need for this sheep to appear in reality. Why was the film designed in that way then? The sheep is a symbol to remind the audience of the relationship between the sheep and Su Cha's corpse. In this way, it echoes the lens of Li Weijie observing the cement floor at the construction site. Without these instructive images, it would be difficult to connect the two. The sheep's body serves as a bridge, which symbolizes another ${ }^{[3]}$.

There is a cognitive difference between capturing the symbols by consciousness and their interpretations. The world of meaning is in fact a world waiting to be realized. In the waiting process, consciousness first designs a scheme to explain symbols in the human brain. Marx wrote in Capital that there is a great difference between man and animal in the meaning of their activities. He stated, "But what distinguishes the worst architect from the best of bees is this, that the architect raises his structure in imagination before he erects it in reality." In the film, the screen language is set before the development of the plot to allow the audience to imagine first. At the 45th-minute of the film, it shows the construction site of a new police station. The close-up shot of the cement floor and the dead sheep suggest that something unusual would happen there. Without these two indicative images, the audience would not be able to think 
of where the body went. The symbols in the earlier part of the film lead to the explanatory significance in the later stage. During this period, the audience's association is conducive to enhancing the sense of substitution. For human consciousness, the temporary absence of meaning is an expectation. Symbol brings meaning lag in the process of waiting, which has become the basic time scale of symbol meaning.

\section{Significance of symbols}

The reason why symbols are needed is that the current meaning is not present, so the presence of symbols can infer the absence of meaning at the moment. Altars and sacrificial activities are used to signify the arrival of gods as humans are not able to directly meet them. In the film, Li Weijie visited the temple twice to give alms. When Li Weijie visited the temple for the second time, the monks did not accept his alms as he was no longer a good man. In this film, the monks are symbols of kindness and justice. The appearance of this symbol shows the absence of justice and kindness. People place their hopes on the gods when justice is not done. At the 88th-minute, La Xuan found Su Cha's body and asked her men to dig up the ancestral grave at Li Weijie's backyard. As a symbol, the grave represents the absence of relatives and friends. It contains the memory of the dead for the living. Therefore, La Xuan's move angered the people in the city.

Human society is composed of symbols. The powerful function of consciousness is to extract useful parts from the complex symbol system and sort them out to obtain orderly logic. This thesis is widely used in crime and suspense films. Evidence is the sorting and refining of symbols by consciousness to prove the truth of absence at a certain time. Evidence is a symbol, and truth is the meaning pursued. In the film, Li Weijie spent a lot of energy weaving a large network for his family to prove their innocence. After the incident, the family's travel, the images left in the monitor, and the disclosure of information to witnesses to urge them to inadvertently perjure, interrogate, and even refine to the retention of various ticket stubs are all the evidence prepared by Li Weijie to conceal his crime. A large network of carefully fabricated evidence is a complete set of symbols. With this set of symbols, Li Weijie can confidently prove the meaning he expresses - innocence. It changes the presence into absence and connects the past and the future with the current symbols.

People's understanding and interpretation are not for the object itself, but for the expected possibilities. The police chief, La Xuan, concluded that Li Weijie was guilty based on her intuition, but her intuition could not be used as evidence. She did not have strong evidence to prove her reasoning. Therefore, although she had seen what Li Weijie had done, she still could not convict Li Weijie because the symbols could not be used as evidence to explain the meaning she wanted to express. The ability of human consciousness to explain meaning is twofold. First, it is to find the meaning of absence in the complex symbols; secondly, consciousness can only explain meaning in its own experience. Seeing is believing. People believe what they see with their own eyes as facts. In that way, Li Weijie succeeded in interpreting the "truth" with "facts" he had created. This is the powerful meaning of symbols.

\section{Conclusion}

Meaning and symbols are like elements in a circle, connected end-to-end and cyclic. Symbol is interpreted as a meaning by consciousness. Consciousness uses another symbol when interpreting the meaning of a symbol. The substitution of symbol is endless in theory. The interpretation of meaning by consciousness is confined to ontological experience. Individual experience is always different. The different meanings received by different audiences depend on each individual's cognitive level and ideological consciousness. Therefore, it is necessary to understand the audience before shooting a film. Relatively speaking, as a popular film, "Manslaughter" accommodates the aesthetic level of the audience to a great extent, thus being its success. 


\section{Disclosure statement}

The author declares that there is no conflict of interest.

\section{References}

[1] Barthes R, 2008, Principles of Semiotics [Li Y, Trans.], China Renmin University Press, Beijing.

[2] de Saussure F, 2011, A Course in General Linguistics [Gao M, Trans.], Commercial Press, Beijing.

[3] Zhao Y, 2018, The First Paradox of Semiotics Is That Symbols are Needed to Explain the Absence of Meaning. Journal of Xihua University (Philosophy and Social Sciences Edition), 37(2): 1-5. 